\title{
Knowledge of future contingents
}

\author{
Andrea Iacona ${ }^{1}$
}

Accepted: 24 May 2021/Published online: 13 June 2021

(C) The Author(s) 2021

\begin{abstract}
This paper addresses the question whether future contingents are knowable, that is, whether one can know that things will go a certain way even though it is possible that things will not go that way. First I will consider a long-established view that implies a negative answer, and draw attention to some endemic problems that affect its credibility. Then I will sketch an alternative line of thought that prompts a positive answer: future contingents are knowable, although our epistemic access of them is limited in some important respects.
\end{abstract}

Keywords Future contingents · Indeterminacy · Open future · Knowledge · Ockhamism · Assertion

\section{The knowability thesis}

Let us start with two simple observations that may easily look obvious to anyone who is not familiar with the subleties of the debate on future contingents. The first is that in some cases it seems that we know that things will go a certain way. The following examples illustrate such cases.

Case 1. Suppose that I set my alarm clock at 6 a.m. because tomorrow I have to catch a train that departs at 8 a.m.. Tonight, before going to bed, I murmur

\section{(1) Tomorrow I'll wake up early}

Understandably, this verbal expression conveys a fairly high degree of confidence. I have reasons to believe that tomorrow at 6 a.m. my phone will emit a distinctive

Andrea Iacona

andrea.iacona@unito.it

1 Department of Philosophy and Education, Center for Logic, Language, and Cognition, University of Turin, Via S. Ottavio 20, 10124 Turin, Italy 
sound, I have reasons to believe that, if my phone will emit that sound, then I will wake up, and so on. On the face of it, these reasons justify my conviction that tomorrow I'll wake up early, which makes it plausible to say that I know (1). ${ }^{1}$

Case 2. Suppose that you got a ticket for a movie and you are talking with a friend who might be interested in joining you. After reading '9 p.m.' on the ticket, you tell her

(2) The movie will start at 9 p.m.

As before, you are fairly confident that the movie will start at 9 p.m., given that you can trust your eyesight, you reasonably believe that the information on the ticket is reliable, and so on. This makes it plausible to say that you know (2).

Case 3. Suppose that Mr Brown is a methodical old man who likes going out for a walk every morning at 10 a.m.. His neighbour, Mrs Green, regularly sees him leaving his house. At 9:50 a.m., while sitting by her window, Mrs Green makes the following statement:

(3) In about $10 \mathrm{~min}$ he will go out

Apparently, Mrs Green has a justification for thinking that Mr Brown will show up as expected: she is aware that Mr Brown is methodical, she has observed many of his past walks, and so on. This makes it plausible to say that Mrs Green knows (3).

The second observation is that, usually, the cases in which it seems that we know that things will go a certain way are cases in which there is a possibility, however remote, that things will not go that way. For example, in case 1 a tsetse fly could bite me during the night and cause me to sleep until noon. Similarly, in case 2 the projectionist could be late, and in case $3 \mathrm{Mr}$ Brown could receive an unexpected visit. Of course, normally we do not think about such possibilities, in that we tend to restrict attention to a limited range of options. But this does not prevent them from existing. It is possible that a tsetse fly bites me during the night, no matter whether I think about it before going to bed.

In other words, the possibility of error is to be understood in terms of objective chance, rather than in terms of subjective or epistemic probability. So, the point does not directly concern claims such as the following:

(4) I know that I will wake up early and it might be that I will not

If 'might' and similar epistemic modals encode an epistemic or subjective notion of probability which differs from the objective notion of chance, as is widely assumed, then the second observation does not entail that (4) is true. To say that knowledge of future events is compatible with some chance of error is not the same thing as to say that it is compatible with some epistemic or subjective probability of error, even though it might indeed be compatible with the latter as well. ${ }^{2}$

\footnotetext{
${ }^{1}$ Here and in the rest of the paper there is no need to be fussy about the distinction between sentences and what they express. When I say that I know (1), I mean that I know the content expressed by (1).

${ }^{2}$ Hawthorne and Lasonen-Aarnio (2009) makes this point clear.
} 
The two observations just outlined, taken together, suggest that future contingents are knowable. That is, they suggest that the following holds for some content $p$ expressed by a future-tense sentence:

(K) There are cases in which one knows $p$ and $p$ is contingent

So it is quite natural to wonder whether $(\mathrm{K})$ can be retained as part of a coherent theory of future contingents.

Although $(\mathrm{K})$ is initially plausible, or at least not patently wrong, its implications may easily give rise to doubts and misgivings. On the standard assumption that knowledge is factive, $(\mathrm{K})$ entails that some contingent $p$ is true. This contradicts the widely held thesis that future contingency is incompatible with truth, call it incompatibilism. That is, $(\mathrm{K})$ is at odds with the conjunction of the following claims:

(F) If one knows $p$, then $p$ is true

(I) If $p$ is contingent, then $p$ is not true

Take any contingent $p$. Given (I), $p$ is not true. Given $(\mathrm{F})$, it follows by contraposition that one does not know $p$. So it seems that, as long as $(\mathrm{F})$ is granted, $(\mathrm{K})$ and $(\mathrm{I})$ cannot stand together. However, I will argue that this is not a good reason to reject $(\mathrm{K})$. The idea that future contingents are knowable, once properly spelled out, proves to be reasonably safe.

The considerations about $(\mathrm{K})$ and $(\mathrm{I})$ presented in the next sections overlap at least in part with considerations that have recently been advanced about the assertibility of future contingents. It is easy to see that the following thesis draws its initial plausibility from the very same kind of examples that speak in favour of $(\mathrm{K})$ :

(A) There are cases in which $p$ is assertible and $p$ is contingent

For example, (1)-(3) seem assertible in the situations described above. (A) clashes with (I) on the assumption that assertibility is factive: if (A) entails that some contingent $p$ is true, then it contradicts (I). As Hattiangadi and Besson have convincingly argued, the clash between (A) and (I) is not a good reason to reject (A). ${ }^{3}$

Although the issue of assertibility will not be discussed here, it may be noted that the rejection of $(\mathrm{K})$ causes the same kind of troubles that arise in connection with the rejection of (A), which suggests that some basic conceptual relation holds between (K) and (A). At least three distinct accounts of assertibility can substantiate this suggestion. One option is to define assertibility in terms of truth, by saying that one can assert $p$ only if $p$ is true. ${ }^{4}$ A second option is define assertibility in terms of justification, by saying that one can assert $p$ only if one is justified in believing $p .^{5} \mathrm{~A}$ third option is to define assertibility in terms of knowledge, by saying that one can assert $p$ only if one knows $p .^{6}$ In each of these three cases, (K) warrants (A), in that

\footnotetext{
${ }^{3}$ Hattiangadi and Besson (2014), Besson and Hattiangadi (2020). (A) has been extensively discussed in the literature on future contingents, see for example Perloff et al. (2001), MacFarlane (2003), Stojanovic (2014), MacFarlane (2014), Santelli (2020).

4 A recent attempt to defend this account is Weiner (2005).

5 This account is developed in different ways in Lackey (2007), Kvanvig (2009), Neta (2009).

6 This account is advocated in Williamson (1996).
} 
knowing $p$ implies that the condition for asserting $p$ is satisfied. However, for our purposes there is no need to spell out the relation between $(\mathrm{K})$ and $(\mathrm{A})$. So it will suffice to observe that there is an interesting parallelism between the issue of knowledge and the issue of assertibility.

\section{Incompatibilism and the difference problem}

In chapter 9 of De interpretatione Aristotle famously argued that future contingents are neither true nor false. His point was that if a sentence such as (1)-(3) were true, then it would be already settled that the event described will occur, and if it were false, then it would be already settled that the event described will not occur. In neither of the two cases the event described would be contingent. ${ }^{7}$

Many contemporary authors agree with Aristotle on this point. The idea that future contingency rules out bivalence underlies several accounts of future-tense sentences. One of them is supervaluationism, the theory developed by Van Fraassen and Thomason, which rests on the idea that future-tense sentences can be evaluated as true or false relative to possible futures. Let a history be a whole possible course of events. Supervaluationism assumes that, for any $p$, there is a set of "accessible" histories such that in each of them $p$ is either true or false. Truth in the non-relative sense - truth simpliciter - is defined in terms of truth relative to histories: $p$ is true if and only if it is true in all histories, and false if and only if it is false in all histories. This definition entails that future contingents are neither true nor false. For example, (1) is neither true nor false because it is true in a history in which I wake up at 6 a.m. but false in a history in which I sleep until noon. ${ }^{8}$

Another theory, due to Belnap, Perloff, and $\mathrm{Xu}$, implies that there is no such thing as truth simpliciter. Future contingents are true or false only relative to histories, because it is only relative to histories that they express a truth-evaluable content. Suppose that (1) is uttered today. Since at the moment of the utterance different futures are possible, each of which includes a different tomorrow, the word 'tomorrow' in (1) does not denote a determinate moment. So it makes no sense to ask whether (1) is true or false. The only meaningful question that can be asked is whether (1) is true or false relative to a given history. This theory shares with supervaluationism the assumption that future-tense sentences can be evaluated as true or false relative to possible futures, but does not identify truth simpliciter with truth in all histories. ${ }^{9}$

A third theory, proposed by MacFarlane, shares with the second the claim that there is no such thing as truth simpliciter, but in this case the idea is that a parameter of evaluation other than the history has to be taken into account. According to MacFarlane, the truth value of a future contingent uttered at a given moment can

\footnotetext{
7 Or at least, this is a widely accepted reading of Aristotle (1984, 18b23 ff).

8 van Fraassen (1966), Thomason (1984). For the sake of simplicity, here and in what follows I will not mention the moment parameter, that is, I will talk about truth relative to histories rather than about truth at moments relative to histories.

9 Perloff et al. (2001).
} 
vary depending on the context of assessment, that is, on the moment in which it is evaluated. Suppose that (1) is uttered today and that I wake up early tomorrow. Today, at the moment of the utterance, (1) is neither true nor false. But tomorrow, once awake, (1) is true. So the same sentence, as uttered at a given moment, can have different truth values in different contexts of assessment. ${ }^{10}$

The three theories just outlined fall under the umbrella of incompatibilism because they entail that future contingents are not true. Surely, they do not exhaust the space under the umbrella. For example, Łukasiewicz's three-valued logic develops the Aristotelian idea in a different way. Moreover, the theory that all future contingents are all false, traditionally attributed to Peirce, entails incompatibilism as well: if $p$ is false in virtue of being contingent, then (I) holds. But for our purposes there is no need to go any further. The discussion that follows concern incompatibilism in general, so it does not depend on specific features of this or that theory. ${ }^{11}$

As we have seen, if (I) is maintained, $(\mathrm{K})$ must be rejected. This is to say that a sentence of the form 'A knows $p$ ' turns out false whenever $p$ is contingent. However, the rejection of $(\mathrm{K})$ has a price. The problem is that the cases such as 1-3 seem to differ from those in which we are typically inclined to say that we do not know what will happen. For each of the three sentences below, it is easy to imagine circumstances in which we lack knowledge of the event predicted:

(5) The coin will land heads

(6) My team will win 3-1

(7) One week from now it will not rain

Imagine that the coin denoted in (5) is fair, that (6) is about the next Champions League Final, and that (7) is uttered in Britain. In such circumstances (5)-(7) are not justified, for there is no adequate evidence for thinking that they are true. In this respect, (1)-(3) clearly differ from (5)-(7). ${ }^{12}$

The difference problem may be phrased in general terms as follows: if the ascriptions of knowledge involving future contingents are all equally false, then what explains the intuitive difference between the cases in which it seems that we know that things will go a certain way and those in which it seems that we lack such knowledge? ${ }^{13}$

In order to appreciate the pervasiveness of the problem it must be noted that 'false' could be replaced by 'untrue' in the formulation above. Although our discussion will focus on the claim that the ascriptions of knowledge involving future contingents are all equally false — obtained by reasoning from (I) and (F) to the negation of (K) - the same problem arises in connection with the claim that the ascriptions of knowledge involving future contingents are all equally indeterminate. This fact is important

\footnotetext{
${ }^{10}$ MacFarlane (2003), MacFarlane (2008).

11 Eukasiewicz (1970). Peirceanism goes back to Prior (1967), and is defended in Todd (2016).

12 Note also that (5)-(7) are clearly not assertible, which makes perfect sense on the assumption that assertibility requires justification.

13 Unless, of course, one wants to deny that in the cases of the first kind the event described is really contingent, as in Scheer (1971).
} 
because a possible move available to the incompatibilist is to block that reasoning by rejecting $(\mathrm{F})$ and arguing that factivity is to be phrased as follows:

$\left(\mathrm{F}^{*}\right) \quad$ If one knows $p$, then $p^{14}$

If one replaces $(\mathrm{F})$ with $\left(\mathrm{F}^{*}\right)$, one may claim that $(\mathrm{K})$ is not false, even though it is indeterminate that one knows $p$ whenever $p$ is contingent. But the problem remains, because we are still without an explanation of the intuitive difference between the cases in which it seems that we know that things will go a certain way and those in which it seems that we lack such knowledge.

This remark also applies to the view advocated by Barnes and Cameron, according to which it is metaphysically indeterminate what will happen: for every contingent $p$, it is determinately the case that $p$ is either true or false, although it is indeterminate which. Barnes and Cameron do not hold a definite position on the question whether future contingents are knowable, and observe that their view is compatible with at least two options. One is that future contingents are not knowable: if $p$ is indeterminate, one cannot know $p$. The other is that the ascriptions of knowledge of future contingents inherit the indeterminacy of future contingents themselves: if $p$ is indeterminate, so is 'A knows $p$ '. Both options face the difference problem: no matter whether the ascriptions of knowledge involving future contingents are taken to be all false or all indeterminate, it has to be explained why some of them seem true while others seem false. ${ }^{15}$

The challenge posed by the difference problem is evident. A brute error theory according to which 'A knows $p$ ' is always false when $p$ is contingent would be hard to swallow, unless it were acompanied by a plausible explanation of why 'A knows $p$ ' seems true in some cases. Sections 3-5 examine three distinct routes that the incompatibilist might take in order to account for the intuitive difference between (1)-(3) and (5)-(7). As we shall see, each of these three routes is more problematic than it may appear at first sight.

\section{Different content}

The first option is to describe the cases in which 'A knows $p$ ' seems true as cases in which A knows some other content $q$ which can easily be mistaken for $p$. More precisely, the incompatibilist might claim that 'A knows $p$ ' is elliptical, in that the real content of A's knowledge is more complex than it appears.

According to one version of this strategy, the real content of A's knowledge is not $p$ itself but the proposition that $p$ is probable, so the cases in which 'A knows $p$ ' seems true are correctly described as cases in which 'A knows that $p$ is probable' is true. For example, the intuitive contrast between (1) and (5) can be explained in terms of the difference between (8) and (9):

\footnotetext{
14 Todd and Rabern (2021, pp. 8-9), discusses the distinction between $(\mathrm{F})$ and $\left(\mathrm{F}^{*}\right)$ in connection with the issue of divine omniscience.

15 Barnes and Cameron (2011, pp. 23-24).
} 
(8) It is probable that tomorrow I'll wake up early

(9) It is probable that the coin will land heads

On the reasonable assumption that I know (8), my apparent knowledge of (1) can be explained in terms of my knowledge of (8). Similarly, on the reasonable assumption that I do not know (9), my apparent lack of knowledge of (5) can be explained in terms of my lack of knowledge of (9). ${ }^{16}$

According to another version of this strategy, the real content of A's knowledge is a conditional whose consequent is $p$ and whose antecedent rules out unforeseen circumstances, such as tsetse flies, delays, or unexpected visits. For example, the intuitive contrast between (1) and (5) can be explained in terms of the difference between (10) and (11):

(10) If nothing very unlikely happens, tomorrow I'll wake up early

(11) If nothing very unlikely happens, the coin will land heads

As in the previous case, it is reasonable to assume that I know (10) but I do not know (11). ${ }^{17}$

Note that (10) and (11) cannot be understood as material conditionals, because the incompatibilist denies that (1) and (5) are true or false. Neither can they be treated as truth-functional trivalent conditionals, for in that case, no matter how the truth-table is defined, they would have the same value as long as (1) and (5) have the same value. The incompatibilist should rather opt for a possible-worlds account according to which (10) differs from (11) because its consequent is true in some relevant set of histories in which its antecedent is true, or for a probabilistic account according to which (10) differs from (11) because the conditional probability of its consequent given its antecedent is high.

No matter whether the content ascribed to A is probabilistic or conditional, however, the claim that 'A knows $p$ ' is elliptical in the sense explained faces at least three problems. We will focus on the probabilistic reformulation to illustrate these problems, although similar considerations hold for the conditional reformulation.

The first problem is that, in order for the proposed explanation to be minimally credible, it must be generally true that 'A knows $p$ ' is to be read as 'A knows that $p$ is probable'. This claim needs be motivated by independent reasons, and it is an open issue whether such reasons can be provided. More specifically, the proposed explanation implies an unlikely asymmetry between future-tense sentences and past-tense sentences, for it does not seem generally true that, when an ascription of knowledge is made by embedding a simple past-tense sentence, the knowledge ascribed has a probabilistic content. If I say that yesterday I woke up early, it seems

\footnotetext{
16 MacFarlane (2014, p. 231), suggests that future-tense sentences can be "clarified" along these lines. Moss (2018, pp. 53-58), argues that simple sentences, including future-tense sentences such as (1) and (5), typically convey probabilistic contents, and suggests that the ascriptions of knowledge that employ simple sentences are to be understood accordingly.

17 MacFarlane (2014, p. 231), also suggest a reformulation along these lines.
} 
that I literally know what I say, that is, what I know is not merely that it is probable that yesterday I woke up early. ${ }^{18}$

Note that this problem does not depend on some specific trait of ascriptions of knowledge, and may equally be raised in connection with the claim that 'A asserts $p$ ' is to be rephrased as 'A asserts that $p$ is probable'. For example, if I say that yesterday I woke up early, it seems that my assertion is to be taken literally, rather than as an assertion that it is probable that yesterday I woke up early. Hattiangadi and Besson have argued against this latter claim by appealing to indirect speech reports. ${ }^{19}$

The second problem concerns future-directed states other than knowledge. If it were generally true that 'A knows $p$ ' is to be read as 'A knows that $p$ is probable', then it would be natural to expect that the same kind of paraphrase applies to ascriptions of other future-directed states, as long as their contents are described by means of the same sentences. But it seems instead that the most plausible reading of such ascriptions is literal. Imagine that I murmur (1) and that my partner, who does not trust my hearing or my determination, says: "I hope so". What does my partner hope? Clearly, she hopes that tomorrow I'll wake up early. She does not hope that it is probable that tomorrow I'll wake up early, because that hope is fulfilled even if I remain in bed and miss my train. The reformulation strategy seems to entail either that the most natural ascription of hope to my partner is wrong, or that (1) has different readings depending of whether it is used to ascribe knowledge or hope.

The third problem concerns retrospective ascriptions of knowledge. Suppose that Mrs Green utters (3) at 9:50 a.m. during a conversation with a friend, and that 10 min later Mr Brown, punctual as always, opens his door and walks out. In this case it seems that Mrs Green can say to her friend: "I knew it! Didn't I tell you?". If we take Mrs Green's words at face value, what she says is that at 9:50 she knew that $\mathrm{Mr}$ Brown would have gone out. Now consider an unlikely parallel scenario in which Mr Brown remains at home because he receives an unexpected visit. In this situation it seems that Mrs Green cannot say the same thing at 10 a.m.. The obvious reason is that, although in both cases Mrs Green was justified in believing (3) at 9:50 a.m., in the second case she did not know (3). If instead the real content of Mrs Green's belief concerned the probability of Mr Brown's walk, then no such distinction could be drawn between the two cases, for in both cases Mrs Green knew at 9:50 that $\mathrm{Mr}$ Brown's walk was probable.

Note that, as in the case of the first problem, the same trouble arises in connection with the claim that 'A asserts $p$ ' is to be rephrased as 'A asserts that $p$ is probable'. If Mrs Green utters (3) at 9:50 a.m., and Mr Brown goes out at 10 a.m., then Mrs Green's friend can say: "You were right!", meaning that the assertion made by Mrs Green at 9:50 was correct. The same statement would be inappropriate in the parallel scenario in which $\mathrm{Mr}$ Brown receives an unexpected visit.

\footnotetext{
18 Of course it might be argued that any simple sentence expresses different contents in different contexts, and only in some of them it expreses a probabilistic content. But some explanation woud still be needed of why in a given context a future-tense simple sentence expresses a probabilistic content whereas the corresponding past-tense sentence do not express such a content.
}

19 Hattiangadi and Besson (2014, p. 267), Besson and Hattiangadi (2020, pp. 495-496). 


\section{Different state or property}

The second option is to describe the cases in which 'A knows $p$ ' seems true as cases in which some non-factive epistemic state or property holds for $p$. At least three versions of this strategy are foreseeable. The first is to say that $p$ is merely believed instead of being known, so the intuitive contrast between (1) and (5) is explained by observing that I believe (1) while I do not believe (5). The second is to say that $p$ is merely justified instead of being known, so the intuitive contrast between (1) and (5) is explained by observing that (1), unlike (5), is justified. The third is to say that $p$ is merely probable instead of being known, so the intuitive contrast between (1) and (5) is explained by observing that (1), unlike (5), is probable. ${ }^{20}$

No matter which of the three versions of the strategy is adopted, the proposed explanation implies a general claim about ascriptions of knowledge involving future contingents. In order for such a claim to be minimally credible, it must be generally true that 'A knows $p$ ' is to be replaced by 'A believes $p$ ', ' $p$ is justified', or ' $p$ is probable'. As in the case of the first option, it is not clear why we should assume that future-tense sentences differ from past-tense sentences in this respect.

Again, the issue of assertibility is analogous in this respect. In order to explain the apparent assertibility of some future contingents, the incompatibilist might appeal to some familiar non-factive act other than assertion-guess, prediction, or conjecture - or define a tailor-made substitute for assertion. But in order for such a claim to be minimally credible, some general revisionary account of assertive utterances must be provided. As Hattiangadi and Besson have argued, this is not an easy task. $^{21}$

Further qualms concern the internal coherence of this option. Consider the first version of the strategy, which replaces knowledge with belief. For any contingent $p$, (I) entails that $p$ is not true. But then it must be wrong to believe $p$, because to believe $p$ is to believe that $p$ is true, or so is reasonable to assume. Thus it must be wrong to believe (1). Yet it does not seem wrong to believe (1). More dramatically, suppose that A knows that $p$ is contingent, and that A endorses (I). Then it seems that A cannot coherently believe $p$, for (I) entails that $p$ is not true. The incompatibilist might certainly deny that belief is linked to truth in the way assumed. But some independent argument would be needed to support such a move. $^{22}$

The second version of the strategy, which replaces knowledge with justification, is less problematic, because it would make little sense to say that it is wrong to have a justification for $p$ when $p$ is not true. Still, it is not entirely obvious that the appeal to justification squares with (I). Suppose, as before, that A knows that $p$ is contingent, and that A endorses (I). Then it is not clear how A can hold that $p$ is justified, since (I) entails that $p$ is not true. One thing is to have a justified belief

\footnotetext{
${ }^{20}$ Note that the third proposal differs from the probabilistic version of the first option because it implies no revisionary claim about content, that is, no content other than $p$ is involved in the explanation.

21 Hattiangadi and Besson (2014, pp. 268-270), Besson and Hattiangadi (2020, pp. 497-499).

22 Cariani and Santorio (2018, pp. 137-138), and Santelli (2020, p. 19), suggest that (I) entails that it is wrong to believe future contingents.
} 
which happens to be untrue, quite another thing is to have a belief and take it to be justified and untrue. Of course, justification may be understood in more than one way, and there is no overt inconsistency in a situation of the second kind. But at least on some understanding of justification, recognizing that $p$ is not true implies reconsidering one's reasons for $p$.

Similar considerations hold for the third version of the strategy, which replaces knowledge with probability. If A knows that $p$ is contingent, and A endorses (I), then A must hold that $p$ is probable and untrue, which seems at odds with the idea that the probability of $p$ is the probability of its truth. A further doubt might be raised in connection with this version. Although knowledge and probability seem to go together in the examples considered, in that (1)-(3) apparently involve both knowledge and probablity while (5)-(7) apparently involve neither of them, there are cases in which knowledge and probability do not go together. Consider the following sentence:

Tomorrow nobody will throw eggs at my window

Although the probability of (12) is very high, it does not seem that I know (12). If I utter (12) in a conversation with a person, that person might naturally ask "How can you say that? You don't know it!". Similar examples come from lottery cases. Suppose that I buy a ticket in a lottery and I utter the following sentence:

My ticket will not win

Although the probability of (13) can be extremely high, this does not necessarily mean that I know (13). Or at least, such ascription of knowledge is controversial. ${ }^{23}$

More generally, it may be argued that probabilty and knowledge differ in the sense that there is a significant mismatch between the class of cases in which the event described is probable and that in which the corresponding ascription of knowledge is plausible. So it is not clear that the difference between the cases in which it seems that we know that things will go a certain way and those in which it seems that we lack such knowledge can be explained in terms of distinction between the cases in which it is probable that things will go a certain way and those in which it is not.

\section{Ignored possibilities}

The third option is to say that 'A knows $p$ ' seems true only insofar as we ignore some possibilities that are relevant given A's epistemic condition: once such possibilities are considered, it becomes clear that A does not really know $p$. Thus, my apparent knowledge of (1) is explained by the fact that I'm ignoring the

\footnotetext{
23 Armstrong (1973, pp. 185-188), Lewis (1996, p. 551), DeRose (1996), Williamson (2000, p. 249), among others, claim that we lack knowledge in the lottery case. Similar considerations hold for assertibility. For example, (12) and (13) are highly probable, but this does not necessarily make them assertible. It may be argued, as in Williamson (2000, p. 246), that high probability by itself does not imply assertibility.
} 
possibility that a tsetse fly bites me. But when that possibility is taken into account, it becomes clear that I do not know (1). More generally, the incompatibilist might argue that our apparent knowledge of future contingents is elusive in the sense suggested by Lewis: as soon as we examine it, straightaway it vanishes. ${ }^{24}$

This line of argument is less compelling than it may seem. First of all, the best way to make sense of the elusiveness claim suggested is to construe it as a claim that specifically concerns future contingents, rather than as a claim that follows from a general view about knowledge. Lewis has defended such a view. According to him, A knows $p$ if and only if A's evidence eliminates every possibility in which not- $p$, except for those possibilities that are properly ignored. Since what is and what is not ignored is a feature of the context, and when a possibility is not ignored, ipso facto is not properly ignored, for every possibility that is properly ignored in a context, there are contexts in which the same possibility is not properly ignored. If the incompatibilist adopted this view, that is, if the point were simply that there are contexts in which the possibility of the tsetse fly is not properly ignored, then the same point would apply to any ascription of knowledge, including 'I know that I have hands'. If all knowledge is elusive in Lewis' sense, the elusiveness of my knowledge of (1) does not depend on its future contingency.

Let it be granted, then, that the problem with ascriptions of knowledge involving future contingents does not reduce to there being contexts in which such ascriptions are false. In this case, the incompatibilist must say that 'A knows $p$ ' is false in every context, or at least in the ordinary contexts in which it seems true. The main problem with this move is that the suggested explanation of the falsity of 'A knows $p$ ' implies that the possibilities ignored are relevant given A's epistemic condition, which is disputable. Unless independent arguments are provided, it cannot be taken for granted that the possibilities that we ignore in the cases in which it seems that we know that things will go a certain way are improperly ignored. In the example considered, it is questionable that the possibility that a tsetse fly bites me is improperly ignored.

As Lewis himself obvserves, it is plausible to think that there is a reliability rule according to which, whenever we employ a process or method that is fairly reliable, we can properly presuppose that the process or method works without a glitch in the case under consideration. In accordance with this rule, it may be argued that there are cases in which it is proper to ignore some possibilities when we predict that things will go a certain way. ${ }^{25}$

Of course, not all ignored possibilities belong to this category. More generally, not all ignored possibilities are properly ignored. But the point is precisely that the delimitation of the class of properly ignored possibilities requires substantive theoretical work. So it is an open question whether the possibilities that are ignored in the cases in which it seems that A knows $p$ really prevent A from knowing $p$.

\footnotetext{
24 Lewis (1996, p. 560).

25 Lewis (1996, p. 558).
} 


\section{Ockhamism}

The foregoing sections show that the difference problem besets incompatibilism with difficulties that deserve careful consideration. This is not to say that they are insurmontable difficulties, or that none of the possible solutions discussed can work. Perhaps the intuitive contrast between (1)-(3) and (5)-(7) might be explained in terms of justification, in accordance with the proposal outlined in Sect. 4. But in that case the incompatibilist should provide independent arguments for the intended reformulation, and spell out a suitable notion of justification. So the details of the story would still be missing. More generally, even though the difference problem may not be a decisive reason against incompatibilism, there is no obvious solution to it.

The aim of the rest of the paper is to sketch a compatibilist view of future contingents which accords with $(\mathrm{K})$. The idea that underlies the view is that one of the possible futures is the actual future, that is, the way things will go. This idea was developed by Ockham in his Tractatus de praedestinatione et praescientia Dei respectu futurorum contingentibus, which is intended to explain how divine foreknowledge is compatible with the contingency of events. If there is such a thing as the actual future, then a principled distinction can be drawn between plain truth, defined as truth in the actual future, and determinate truth, defined as truth in all possible futures. So it turns out that future contingents are true or false, even though they are neither determinately true nor determinately false. ${ }^{26}$

Ockhamism is consistent with different metaphysical conceptions. At least two basic distinctions must be taken into account in order to spell out the relation between the actual future and the other possible futures. The first is between real possibilities and ersatz possibilities: possible futures, just as the histories to which they belong, can be understood either as concrete entities that exist in the most fundamental sense, or as abstract entities built from sentences, propositions, or other kinds of actual items. The second is between branching and divergence: one thing is to claim that histories can overlap, as in Fig. 1, so that two distinct possible futures can share a single past, quite another thing is to claim that histories are entirely disconnected totalities, as in Fig. 2, so that distinct possible futures always have distinct pasts.

In the literature on future contingents, Ockhamism is often associated with the view that the actual future is a distinguished member of a set of real possible futures that branch for a single past. So, for example, in the case of Fig. 1 the idea is that $h_{1}$ and $h_{2}$ are equally real, but one of them, say $h_{1}$, is the actual history. This view, also known as the thin red line, has been mainly discussed by the opponents of Ockhamism. $^{27}$

\footnotetext{
26 Ockham (1978, pp. 515-517). This view is elaborated and defended in Øhrstrøm (2009), Rosenkranz (2012), Iacona (2013), Wawer (2014), Malpass and Wawer (2020).

27 The expression 'thin red line' goes back to Belnap and Green (1994). The view is discussed in Perloff et al. (2001), and in MacFarlane (2003), among other works. Some of their objections are countered in Rosenkranz (2012), Borghini and Torrengo (2013), Iacona (2014).
} 
However, neither real possibilities nor branching are essential to Ockhamism. As far as the Ockhamist analysis of truth is concerned, non-actual futures can equally be conceived as ersatz possibilities. Arguably, it is not even necessary that the actual future itself is assumed to be real in the same sense in which the present is real. Of course, it might be contended that ersatz branching is not "real" branching. But then the question becomes whether there are reasons to value "real" branching per se. ${ }^{28}$

The alternative to branching is divergence. In this case the idea is that we have a single future because we belong to a single history, the actual history, although other histories are exactly like our history up to the present. Thus, Fig. 2 can be taken to represent the actual history, say $h_{1}$, and a wholly distinct history that is exactly like $h_{1}$ up to a certain point. As in the case of Fig. $1, h_{2}$ can be understood either as a real possibility or an ersatz possibility. Lewis has advocated divergence in a metaphysical framework where possible worlds are taken to be just as real as the actual world. But it is not necessary to buy the whole of Lewis's metaphysics in order to accommodate Ockhamism. ${ }^{29}$

\section{The metaphor of openness}

Although Ockhamism has received growing attention lately, it is far from being popular. The main worry that has been raised in connection with it is that the very notion of future actuality seems at odds with the widely accepted claim that the future is open. However, I believe that this worry is ungrounded. The claim that the future is open can be understood in more than one way, and it is questionable that the most plausible interpretations of it are inconsistent with Ockhamsim.

Independently of whether non-actual histories are real or ersatz possibilities, or whether they branch or diverge, Ockhamism leaves room for at least three plausible readings of the metaphor of openness. A first option is to define openness in terms of existence of alternative possibilities: to say that the future is open is to say that, for some $p$, both $p$ and not- $p$ are possible. This interpretation equates the claim that the future is open with the negation of fatalism, the doctrine that no future event is contingent. If openness is defined in terms of existence of alternative possibilities, the claim that the future is open is clearly consistent with Ockhamism, for it boils down to the claim that some $p$ is neither determinately true nor determinately false.

A second option is to define openness in terms of indetermination, understood as absence of determination: to say that the future is open is to say that nothing determines the future. Determination may be defined as a relation between states: given a state $S$ that obtains at time $t_{0}$ and given a state $S^{\prime}$ that obtains at time $t_{1}, S$ determines $S^{\prime}$ if and only if the obtaining of $S$ at $t_{0}$, together with the laws of nature, entails that $\mathrm{S}^{\prime}$ obtains at $t_{1}$. If openness is defined in terms of indetermination, the claim that the future is open is clearly consistent with Ockhamism, for future

\footnotetext{
28 Iacona (2021) provides a thorough discussion of the metaphysical views consistent with Ockhamism.

29 Lewis (1986, p. 206).
} 
Fig. 1 Branching
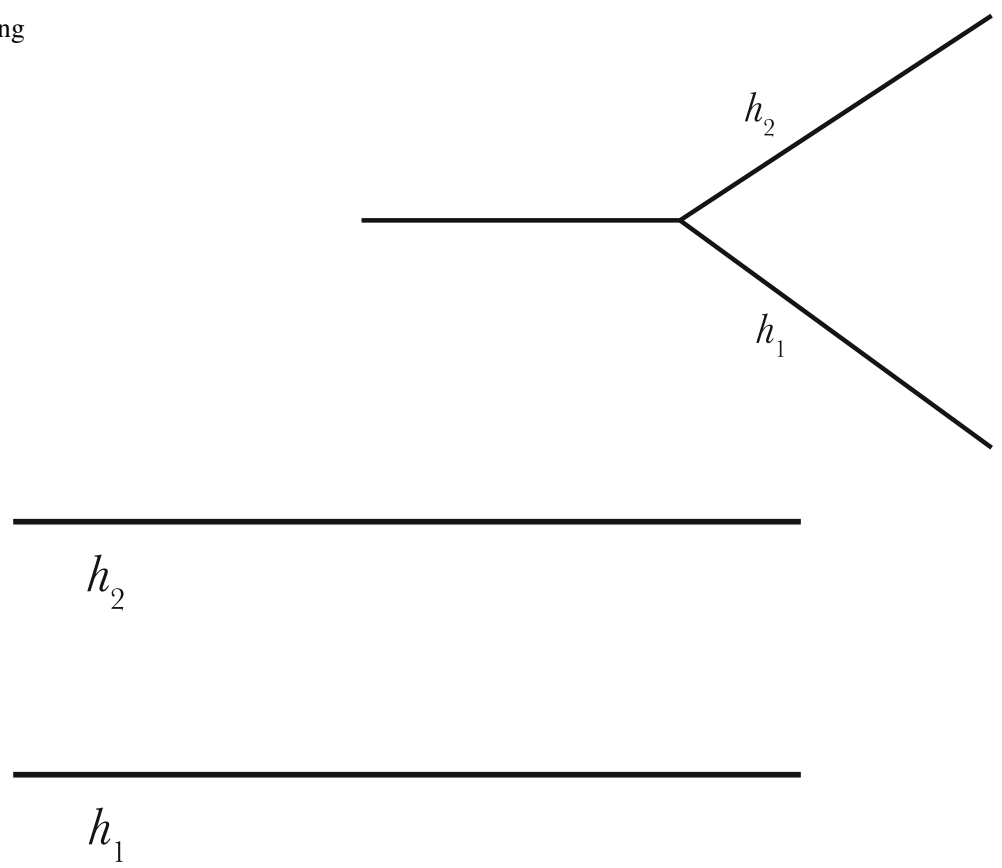

Fig. 2 Divergence

actuality does not entail determination: the actual future can instantiate two states $\mathrm{S}$ and $\mathrm{S}^{\prime}$ such that $\mathrm{S}$ does not determine $\mathrm{S}^{\prime}$.

A third option is to define openness in terms of our capacity to cause future events. For example, if I set the alarm of my phone at 6 a.m., the sound that the phone will emit tomorrow morning is an effect of the movements that I perform tonight. Clearly, the past does not depend on us in this sense, because our present actions do not have past effects. No matter whether I set the alarm or not, what happened yesterday remains the same. If openness is understood this way, the claim that the future is open is clearly consistent with Ockhamism, for it makes perfect sense to say that an event which occurs in the actual history at a given time causes another event that occurs in the actual history at a later time. ${ }^{30}$

The three interpretations considered do not exhaust the possible readings of the metaphor of openness, and one can surely find some other interpretation that differs from them and contradicts Ockhamism. In particular, if one is a branching purist who thinks that temporal reality is constituted by plurality of overlapping worlds that are equal in all respects, one may be apt to identify openness with this very conception. ${ }^{31}$

\footnotetext{
${ }^{30}$ As Lewis (1979) suggests, the asymmetry between future and past can be described in terms of counterfactual dependence.

${ }^{31}$ MacFarlane (2003), and Spolaore and Gallina (2018) adopt a definition along these lines.
} 
The problem with such an interpretation, however, is that it is too theoretically loaded to be regarded as purely intuitive. Whatever our intuitions about the future may be, they are not as specific and fine-grained as to settle the question whether possible worlds overlap. The nature of possible worlds and the relations between them are matter of metaphysical controversy. Therefore, an appeal to openness so understood can hardly be used against Ockhamism as if it were an appeal to the intuition of openness. ${ }^{32}$

Branching purists, however, tend to reason in this way when they dismiss Ockhamism-or the thin red line-as an untenable variant of their own conception. In order to illustrate the frailty of their misgivings, we will consider two examples. The first is drawn from Belnap, Perloff, and $\mathrm{Xu}$ :

What in the structure of our world could determine a single possibility from among all the others to be 'actual'? As far as we know, there is nothing in any science that would help. To the extent that scientific theories require objective possibilities for the future, there is no hint that those theories pick out a Thin Red Line. ${ }^{33}$

This negative remark is misguided in at least two respects. First, the appeal to scientific theories is out of place here, for scientific theories-just like intuitionsdo not settle the main metaphysical questions about the future. In particular, they do not indicate branching purism as the best metaphysical view. As far as scientific theories are concerned, the metaphysical options considered in Sect. 6 are all equally admissible. Second, future actuality does not entail determination, as noted above: something can belong to the actual future without being determined. One thing is to say that a given history is the actual history, quite another thing is to say that something in the structure of the world determines it to be actual. The first claim does not entail the second. Once the suspicion of determination is dispelled, asking the Ockhamist why the actual history is actual, rather than merely possible, is like asking anyone else why the actual world is actual, rather than merely possible.

The second example, drawn from McArthur and MacFarlane, is the objection according to which if one of the branches of the tree is the actual history, it is no longer clear how the other branches can represent genuine possibilities:

But, in our view, allowing any state to already be marked as that which will become actual, or as that state which is (atemporally) actual, reintroduces the linear conception, because it denies that the other states are real alternatives. ${ }^{34}$

I hold that positing a thin red line amounts to giving up objective indeterminism. The non-red branches in the tree are supposed to represent objectively possible futures, but their non-redness indicates precisely that they

\footnotetext{
32 Torre (2011, pp. 367-368), contains some remarks along these lines.

33 Perloff et al. (2001, p. 162).

34 McArthur (1974, p. 284).
} 
will not be the continuations of the history that includes the utterance in question. [...] In what sense, then, are the others really 'possibilities' ${ }^{35}$

This objection is misguided as well. Consider Fig. 1. Let $f_{1}$ and $f_{2}$ be the nonoverlapping segments of $h_{1}$ and $h_{2}$ respectively, and suppose as before that $h_{1}$ is the actual history. It is certainly legitimate to ask whether $f_{2}$ is a genuine continuation of the part of $h_{1}$ that precedes $f_{1}$. But a negative answer to this question is not to be confused with the claim that $f_{2}$ is not a a genuine possibility. The mere non-actuality of $f_{2}$ does not prevent it from being possible, just as the fact that I'm not actually lying on a beach does not prevent such a state of affairs from being possible. So, there is a clear sense in which positing a thin red line does not amount to giving up objective indeterminism. Perhaps it amounts to giving up "real" branching. But then, as noted in Sect. 6, the question becomes whether there are reasons to value "real" branching per se. Branching purists cannot take for granted that branching and indeterminism are the same thing, because the Ockhamist is under no obligation to agree on this point. ${ }^{36}$

\section{True ascriptions of knowledge}

Ockhamism is consistent with $(\mathrm{K})$. As we have seen, incompatibilism is at odds with $(\mathrm{K})$ because there is a valid reasoning that goes from (I) and $(\mathrm{F})$ to the negation of (K). Ockhamism blocks that reasoning because it rejects (I). So it does not require revisionary strategies such as those discussed in Sects. 3-5. The observation that in some cases it seems that we know that things will go a certain way must not be explained away in terms of a systematic paraphrase of the sentences of the form 'A knows $p$ ', for it can be granted that some sentences of that form are literally true.

In order to illustrate this point, I will assume divergence, leaving unspecified whether non-actual histories are real or ersatz possibilities. Consider Fig. 3, and let $h_{1}$ be the actual history. $h_{1}$ and $h_{2}$ include two distinct presents, $m_{1}$ and $m_{2}$. Assuming that there is an absolute temporal axis, that is, that time can be measured from a point of view that is external to the histories, we can say that $m_{1}$ and $m_{2}$ are located at the same point along that axis. If we call instant an absolute temporal unit, definable as a set of equivalent moments, we can say that $m_{1}$ and $m_{2}$ are in the same instant, $i_{0}$. This instant is represented as a vertical line that intersects $h_{1}$ and $h_{2}$.

It is important to note that being in a given history does not mean being in a position to discern that history from other histories. Suppose that $h_{1}$ and $h_{2}$ are exactly alike up to $i_{0}$, and that a person $\mathrm{A}$ is in $m_{1}$. For $\mathrm{A}, m_{1}$ is indistinguishable from $m_{2}$, and the same goes for any pair of moments in any instant that precedes $i_{0}$. This is to say that $\mathrm{A}$ is not in a position to know whether the actual history is $h_{1}$ or $h_{2}$. If some event occurs in $h_{1}$ after $m_{1}$ but does not occur in $h_{2}$ after $m_{2}$, A is not in a

\footnotetext{
35 MacFarlane (2003, p. 325).

36 Iacona (2013) provides a detailed discussion of the main objections to Ockhamism, including those just considered.
} 


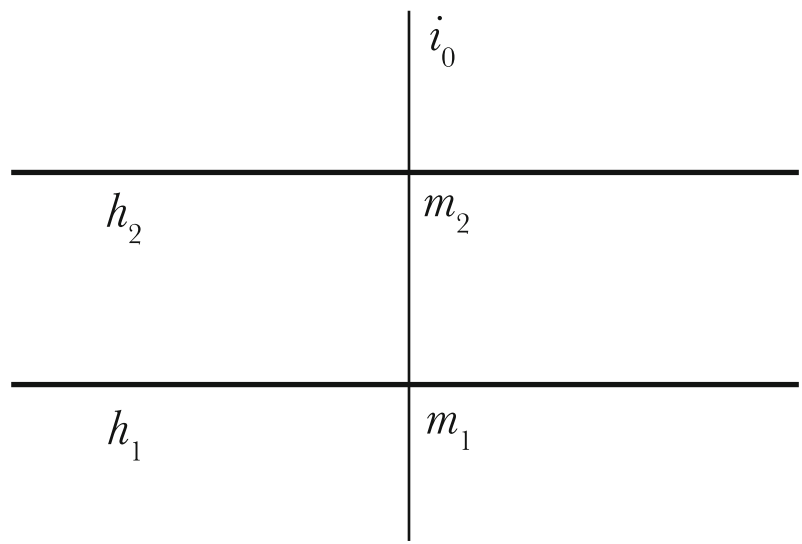

Fig. 3 Two pasts, two presents, two futures

position to know whether the occurrence of that event belongs to the actual history. In a way, we do not know what will happen because we do not know where we are.

Now suppose that $h_{1}$ and $h_{2}$ are exactly alike up to $i_{0}$, as before, and that some specific difference between $h_{1}$ and $h_{2}$ that matters to the truth of $p$ is located at an instant $i_{1}$ later than $i_{0}$. Imagine for example that $i_{0}$ is today, $i_{1}$ is tomorrow, and $p$ is a statement uttered today about some event that can occur tomorrow. In Fig. 4, $m_{1}$ and $m_{2}$ are qualitatively identical moments, while $m_{3}$ and $m_{4}$ are qualitatively different moments: $m_{3}$ makes $p$ true, while $m_{4}$ makes it false. This is to say that $p$ is true relative to $h_{1}$, and false relative to $h_{2}$. Whether $p$ is true or false simpliciter depends on which of the two histories is the actual history. In any case, $p$ is either true or false, even though it is neither determinately true nor determinately false.

In a situation of this kind it is conceivable that $p$ is true, and that a person $\mathrm{A}$, at $i_{0}$, satisfies the epistemic condition - whatever it may be-that is required to know $p$. So it can be the case that 'A knows $p$ ' is true. Cases 1-3 are precisely situations of this kind. For example, it is conceivable that I really know (1), just as it appears, because (1) is true in the actual history, and I have all that is required to know (1). Similar considerations hold for (2) and (3).

\section{Reasonable ascriptions of knowledge}

As we have seen, $(\mathrm{K})$ owes its initial plausibility to the fact that some sentences of the form 'A knows $p$ ' seem true even though $p$ is contingent. The foregoing sections suggest that there is a coherent way to claim that some of these sentences are really true. However, it is important to understand that this claim does not entail that all the apparently true sentences of the form 'A knows $p$ ' are really true.

Any person $\mathrm{B}$ who ascribes knowledge of $p$ to $\mathrm{A}$ can have at most a defeasible warrant to think that $p$ is true. So it can happen that B rationally believes that $\mathrm{A}$ knows $p$ but $p$ is false. Since knowledge entails truth, the cases of this kind are cases in which A does not know $p$, so B's ascription is false. Of course, this also holds 


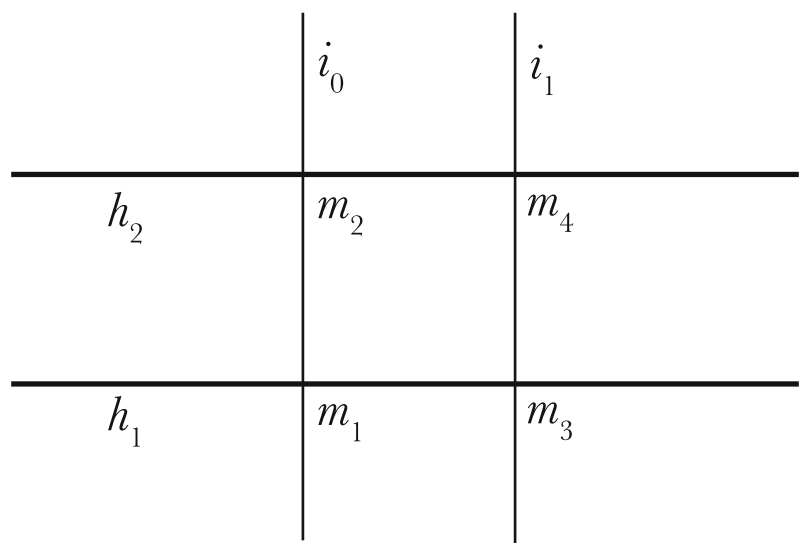

Fig. 4 Two todays and two tomorrows

when $\mathrm{A}$ and $\mathrm{B}$ are the same person: it can happen that $\mathrm{A}$ rationally believes that $\mathrm{A}$ knows $p$ but $p$ is false.

Consider case 1 . When I utter (1) it seems that I know what I say. But I cannot rule out the possibility that a tsetse fly bites me. Suppose that $h_{1}$ and $h_{2}$ are qualitatively identical up to $i_{0}$, as in Fig. 4, and that I utter (1) at $i_{0}$. Suppose also that $i_{1}$ is tomorrow at 6 a.m., that $m_{3}$ is the predictable moment in which I wake up, and $m_{4}$ is the unlikely scenario in which I remain in bed because of the tsetse fly. In this case, I'm unable to tell whether I' $m$ in $h_{1}$ or in $h_{2}$. If I am in $h_{1}$, as is reasonable to believe, then I really know (1). If instead I am in $h_{2}$, then I do not know (1).

Similar considerations hold for cases 2 and 3. Although it seems that you know (2), it can happen that the projectionist is late, hence that you do not really know (2). Similarly, although it seems that Mrs Green knows (3), it can happen that Mr Brown has an unexpected visitor, hence that Mrs Green does not really know (3). More generally, for any case in which it seems that 'A knows $p$ ' is true, it can happen that 'A knows $p$ ' is false because $p$ is false. This explains why retrospective ascriptions of knowledge are intuitively incorrect when $p$ turns out to be false, as noted in Sect. 3.

But then, if we cannot take for granted that all the apparently true sentences of the form 'A knows $p$ ' are really true, how can we account for their apparent truth? The answer is that the cases in which 'A knows $p$ ' seems true are cases in which the ascription of knowledge is reasonable. Consider case 1 . Since it is very probable on my present evidence that I know (1), it is reasonable for me to believe that I know (1). Of course, if a tsetse fly bites me, I don't really know (1). But this does not prevent my self-ascription of knowledge from being reasonable. Similar considerations hold for cases 2 and 3. The intuitive distinction between (1)-(3) and (5)-(7) lies in the fact that it is reasonable to think that we know (1)-(3) while it is not reasonable to think that we know (5)-(7).

More generally, suppose that it is very probable on B's evidence that A knows $p$, but that $\mathrm{B}$ is not in a position to tell whether $\mathrm{A}$ really knows $p$ or $\mathrm{A}$ falsely but reasonably believes $p$. Then it is reasonable for B to ascribe knowledge to A, 
independently of whether A really knows $p$. If $\mathrm{A}$ and $\mathrm{B}$ are the same person, this means that it is reasonable for A to make a self-ascription of knowledge, independently of whether the ascription is actually true.

Note that the explanation just outlined is largely neutral as to the question of what is knowledge. On any account of knowledge, A knows $p$ just in case some suitably defined condition $\mathrm{C}$ obtains, where $\mathrm{C}$ entails that $p$ is true. All that needs be assumed here is that the cases in which it seems that we have knowledge-such as cases 1-3 - are cases in which it is reasonable to think that $\mathrm{C}$ obtains, independently of whether $p$ is actually true, while the cases in which it seems that we lack knowledge are cases in which it is not reasonable to think that $\mathrm{C}$ obtains. This assumption is consistent with different accounts of knowledge.

\section{The KK principle}

A further issue concerns second-order knowledge. According to a widely debated principle, second-order knowledge follows from first-order knowledge:

(KK) If one knows $p$, then one knows that one knows $p$

Since the explanation outlined in the foregoing section is largely neutral as to the question of what knowledge is, the same goes for the question whether (KK) holds, given that the latter question essentially depends on the former. For at least some account of knowledge consistent with $(\mathrm{K})$, it can happen that one knows $p$ without knowing that one knows $p$.

Suppose that it is very probable on A's evidence that A knows $p$, but that A is not in a position to tell whether $p$ is true or A falsely but reasonably believes $p$. Suppose in addition that $p$ is true, so that $\mathrm{A}$ really knows $p$. It is an open question whether in such circumstance A knows that A knows $p$. Consider again case 1 , in which it is very probable on my present evidence that I know (1) but I'm unable to tell whether (1) is really true or I falsely but reasonably believe (1). Now suppose that (1) is true, so that I really know (1). It is an open question whether in such circumstance I know that I know (1), given that I'm not in a position to rule out that a tsetse fly will bite me.

The possible failure of $(\mathrm{KK})$ constitutes a further limitation that must be taken into account in order to fully grasp the knowability thesis. Any plausible defence of (K) must recognize that our knowledge of future contingents is limited in at least two respects. First, for every case in which it seems that we know $p$, it can happen that we do not $p$ because $p$ is false. Second, it cannot even be taken for granted that, when we know $p$, we are in a position to know that we know $p$.

When Ockham argued that divine foreknowledge is compatible with the contingency of events, he conceived of God's intelligence as a perfect faculty free from such limitations. For every contingent $p$, God knows $p$. Otherwise, there would be something that God does not know. Moreover, for every contingent $p$ such that God knows $p$, God also knows that he knows $p$. Otherwise, again, there would be something that God does not know. We are definitely unlike God in the first respect because we are totally ignorant about many future contingents. But we might also be 
unlike God in the second respect: we might be unable to discern the future contingents we know from those we do not know.

Acknowledgements I presented this paper at the Centre of Philosophy of the University of Lisbon in the spring of 2019, and I'm very grateful to the audience of that talk, especially Ricardo Santos and Elia Zardini, for the helpful feeback. I would also like to thank Fabrizio Cariani, Enzo Crupi, Stephan Torre, and an anonymous reviewer for their accurate and constructive comments on previous versions of the text.

Funding Open access funding provided by Università degli Studi di Torino within the CRUI-CARE Agreement.

Open Access This article is licensed under a Creative Commons Attribution 4.0 International License, which permits use, sharing, adaptation, distribution and reproduction in any medium or format, as long as you give appropriate credit to the original author(s) and the source, provide a link to the Creative Commons licence, and indicate if changes were made. The images or other third party material in this article are included in the article's Creative Commons licence, unless indicated otherwise in a credit line to the material. If material is not included in the article's Creative Commons licence and your intended use is not permitted by statutory regulation or exceeds the permitted use, you will need to obtain permission directly from the copyright holder. To view a copy of this licence, visit http:// creativecommons.org/licenses/by/4.0/.

\section{References}

Aristotle. (1984). De Interpretatione. In J. Barnes (Ed.), The Complete Works of Aristotle (Vol. 1, pp. 25-38). Princeton: Princeton University Press.

Armstrong, D. M. (1973). Belief, truth and knowledge. Cambridge: Cambridge University Press.

Barnes, E., \& Cameron, R. (2011). Back to the open future. Philosophical Perspectives, 25, 1-26.

Belnap, N., \& Green, M. (1994). Indeterminism and the thin red line. In J. Tomberlin (Ed.), Philosophical perspectives (Vol. 8, pp. 365-388). Atascadero: Ridgeview.

Borghini, A., \& Torrengo, G. (2013). The metaphysics of the thin red line. In F. Correia \& A. Iacona (Eds.), Around the tree: Semantic and metaphysical issues concerning branching and the open future (pp. 105-125). Chaim: Springer.

Besson, C., \& Hattiangadi, A. (2010). Oxford handbook of assertion, chapter assertion and the future (pp. 481-504). Oxford: Oxford University Press.

DeRose, K. (1996). Knowledge, assertion and lotteries. Australasian Journal of Philosophy, 74, 568-580.

Cariani, F., \& Santorio, P. (2018). Will done Better: Selection semantics, future credence, and indeterminacy. Mind, 127, 129-165.

Hattiangadi, A., \& Besson, C. (2014). The open future, bivalence and assertion. Philosophical Studies, 162, 251-271.

Hawthorne, J., \& Lasonen-Aarnio, M. (2009). Knowledge and objective chance. In P. Greenough \& D. Pritchard (Eds.), Williamson on knowledge (pp. 92-108). Oxford: Oxford University Press.

Iacona, A. (2013). Timeless truth. In F. Correia \& A. Iacona (Eds.), Around the tree: Semantic and metaphysical issues concerning branching and the open future (pp. 29-45). Chaim: Springer.

Iacona, A. (2014). Ockhamism without thin red lines. Synthese, 191, 2633-2652.

Iacona, A. (2021). The metaphysics of ockhamism. In A. Santelli, (Eds.), Ockhamism and philosophy of time: Semantic and metaphysical issues concerning future contingents. Springer (forthcoming).

Kvanvig, J. L. (2009). Assertions, knowledge, and lotteries. In P. Greenough \& D. Pritchard (Eds.), Williamson on knowledge. Oxford: Oxford University Press.

Lackey, J. (2007). Norms of assertion. Noûs, 41, 594-626.

Lewis, D. (1979). Counterfactual dependence and time's arrow. Noûs, 13, 455-476. 
Lewis, D. (1986). On the plurality of worlds. Oxford: Blackwell.

Lewis, D. (1996). Elusive knowledge. Australasian Journal of Philosophy, 74, 549-567.

Łukasiewicz, J. (1970). On three-valued logic (1920). In L. Borkowski (Ed.), Selected works (pp. 87-88). Amsterdam: North-Holland.

MacFarlane, J. (2003). Future contingents and relative truth. Philosophical Quarterly, 53, 321-336.

MacFarlane, J. (2008). Truth in the garden of forking paths. In M. García-Carpintero \& M. Kölbel (Eds.), Relative truth (pp. 81-102). Oxford: Oxford University Press.

MacFarlane, J. (2014). Assessment sensitivity. Oxford: Oxford University Press.

Malpass, A., \& Wawer, J. (2020). Back to the actual future. Synthese, 197, 2193-2213.

McArthur, R. P. (1974). Factuality and modality in the future tense. Noûs, 8, 283-288.

Moss, S. (2018). Probabilistic knowledge. Oxford: Oxford University Press.

Perloff, M., Belnap, N., \& Xu, M. (2001). Facing the future. Oxford: Oxford University Press.

Neta, R. (2009). Treating something as a reason for action. Noûs, 43, 684-699.

Ockham, W. (1978). Tractatus de praedestinatione et de praescientia dei respectu futurorum contingentibus. In Opera philosophica et theologica, volume II. The Franciscan Institute, St. Bonaventure, New York.

Øhrstrøm, P. (2009). Linein defence of the thin red: A case for Ockhamism. Humana Mente, 8, 17-32.

Prior, A. N. (1967). Past, present and future. Oxford: Clarendon Press.

Rosenkranz, S. (2012). Defence of Ockhamism. Philosophia, 40, 617-31.

Santelli, A. (2020). Future contingents, branching time and assertion. Philosophia: Springer.

Scheer, R. K. (1971). Knowledge of the future. Mind, 80, 212-226.

Spolaore, G., \& Gallina, F. (2018). The actual future is open. Erkenntnis, 85, 99-119.

Stojanovic, I. (2014). Talking about the future: Unsettled truth and assertion. In P. De Brabanter, M. Kissine, \& S. Sharifzadeh (Eds.), Future times, future tenses. Oxford: Oxford University Press.

Thomason, R. H. (1984). Combinations of tense and modality. In D. Gabbay \& G. Guenthner (Eds.), Handbook of philosophical logic (Vol. 2, pp. 135-165). Dordrecht: Reidel.

Todd, P. (2016). On behalf of a mutable future. Synthese, 193, 2077-2095.

Todd, P., \& Rabern, B. (2021). Future contingents and the logic of temporal omniscience. Not̂s, 55, $102-127$.

Torre, S. (2011). The open future. Philosophy Compass, 5, 360-373.

van Fraassen, B. (1966). Singular terms, truth-value gaps, and free logic. Journal of Philosophy, 63, $481-495$.

Wawer, J. (2014). The truth about the future. Erkenntnis, 79, 365-401.

Weiner, M. (2005). Must we know what we say? Philosophical Review, 114, 227-251.

Williamson, T. (1996). Knowing and asserting. Philosophical Review, 105, 489-523.

Williamson, T. (2000). Knowledge and its limits. Oxford: Oxford University Press.

Publisher's Note Springer Nature remains neutral with regard to jurisdictional claims in published maps and institutional affiliations. 